\title{
EDITORIAL
}

\section{Artículo científico: pautas para elaborar la Metodología}

Algo fundamental que se pide cumplir en la sección Metodología de un trabajo científico es el "criterio de reproducibilidad". Este criterio es inherente al trabajo que realiza todo científico; se dice que, sin él, la ciencia no es ciencia, si un resultado no se puede reproducir no se pude comprobar.

Se debe especificar los MATERIALES en cuanto a: origen/procedencia, características generales, grado de pureza, número de lote, fabricante, etc. En el caso de los MÉTODOS se pueden redactar de tres formas: (a) mencionando el método y colocando la fuente bibliográfica donde el método está publicado; (b) mencionando el método y redactando lo que fue adaptado, con mención también de la fuente bibliográfica donde el método original fue publicado; y (c) mencionando el método sin fuente bibliográfica, cuando el método es propio.

La metodología se puede dividir en secciones en función de los objetivos específicos del estudio; pero no se debe crear secciones para materiales y/o de equipos, salvo que sea necesario describir el objeto de estudio, principalmente cuando este aspecto inicial, tenga influencia en el resultado final.

Los materiales y equipos más importantes se van mencionando a medida que se describe el método. Un criterio que ayuda a la reproducibilidad son las precisiones o características (modelo, marca, país de fabricación) sobre maquinaria, equipos o instrumentos utilizados.

La metodología se puede describir sólo en texto, aunque de ser necesario se pueden utilizar figuras (mapas, esquemas, flujogramas, imágenes, etc.), tablas y ecuaciones. En trabajos donde la estadística juega un papel muy importante, es necesario indicar la prueba estadística, el nivel de significancia, el uso que se le dio a la prueba estadística y el software utilizado. 